\title{
Magnetotransport Properties of Co-Au Granular Alloys
}

\author{
Conrad Rizal, Member IACSIT, Yuji Ueda, and Ramesh K. Pokharel
}

\begin{abstract}
A series of Cox-Au1-x granular alloys was grown using pulsed-current electrodeposition on polyimide substrates. The relationship between the giant magnetoresistance effect, saturation magnetization, and grain size was examined as the deposition current density and annealing temperatures were changed. A maximum magnetoresistance (MR) ratio of $4.5 \%$ was obtained. The magnetization and ferromagnetic grain size of the as-deposited and annealed alloy films were examined against the deposition current density. The saturation magnetization decreased as the composition of Au was increased for both the alloys deposited at the current densities of 1 and $5 \mathrm{~mA} / \mathrm{cm} 2$. The total magnetic moment further decreased on annealing. The grain size is found to be highly influenced by both the deposition current density and temperature. A low temperature magnetization measurement suggested that the ferromagnetic grain size decreases with increase in current densities. For the annealed samples, the ferromagnetic grain sizes were found to be dispersed in the $\mathrm{Au}$ matrix with different diameters. The decrease in magnetic moments with annealing is correlated with the grain size of the Co and its distribution in the gold matrix. The MR ratio increased with the increase in the deposition current density as a result of the formation of smaller grain size at higher deposition current densities.
\end{abstract}

$\begin{array}{ccccc}\text { Index } & \text { Terms-Co-Au } & \text { granular } & \text { alloys, giant } \\ \text { magnetoresistance } & \text { effect, } & \begin{array}{l}\text { saturation } \\ \text { magnetization, }\end{array}\end{array}$
ferromagnetic grains

\section{INTRODUCTION}

Magnetic alloys with interesting magnetotransport and magnetic properties have been the subject of intense investigations due to their significance in fundamental physics [1]-[5] and application in electronics [6], [7] and in the automobile [8], [9], and biomedical sectors [10]-[13]. Many novel nanomaterials have been developed from the combination of ferromagnetic 3-d transition metals and non-magnetic group IB metals at an atomic scale [6], [14]-[20], and more are expected to emerge as the research continues. Usually, 3-d transition ferromagnetic metals exhibit MR effect by virtue of their nature as these materials possess interesting electronic configurations where the $4 \mathrm{~s}$ sub-shells are occupied leaving behind their 3-d shells unfilled. This phenomenon we can understand from the

Manuscript received October 11, 2011; revised November 20, 2011.

This work was supported in part by a Natural Science and Engineering Research Council of Canada.

C. Rizal is with the Department of Electrical and Computer Engineering, University of British Columbia, Vancouver, BC, V6T 1Z4, Canada (corresponding author: +1-604-822-6268; fax:+1-604-822-5949; e-mail:crizal@ece.ubc.ca).

Y. Ueda is with the Department of Electrical and Electronic Engineering, Muroran Institute of Technology, 27-1, Mizumoto-cho, Muroran-shi, Hokkaido, 050-8585, Japan. (e-mail:ueda@mmm.muroran-it.ac.jp). His current status is a Professor Emeritus.

R. K. Pokharel is with the E-JUST Center, Department of Electrical and Communication Engineering, Kyushu University, Fukuoka, 819-0395, Japan. (e-mail: pokharel@ed.kyushu-u.ac.jp). electronic configurations of these metals. On the application of an magnetic field, these 3-d transition metals exhibit interesting anisotropic magnetoresistance effect, which is a change in electrical resistance, where there is a difference between the MR values when the magnetic field is applied parallel and perpendicular to the direction of current [3]. The degree of anisotropy in transition metals is a function of magnetic moment and the angle that it makes with the direction of current. The mechanism of AMR is considered to be due to the interactions of 3-d and 4-s electrons of the ferromagnetic metals [7]. On the other hand, when we combine 3-d transition metals with the group IB non-magnetic metals, they form magnetic multilayers, alloys, and nanoparticles that exhibit GMR effect. What makes the GMR effect different from the AMR effect is its magnitude, which is relatively much larger than the AMR effect reported so far [7], [21]. Also, the magnitude of GMR is independent of the direction of current or applied magnetic field [22]. The mechanism of GMR effect in Co-Au is considered to be due to the interaction of $4 \mathrm{~s}$ electrons of $\mathrm{Au}$ and $3 \mathrm{~d}$ electrons of Co [3], [23]. For practical alloys, not only should we consider the spin alignments along the cross section of the film but also consider the spin arrangements along the surface of the film [22], [23].

Most of these granular alloys have been grown using non-aqueous methods such as sputtering [24], molecular beam epitaxy [25], e-beam evaporation [26], melt spun [27], and mechanical alloying [14]. However, the relationship between various preparation conditions and giant magnetoresistance (GMR) effect, a large change in electrical resistance at the low applied magnetic field, and magnetic properties has not been clear yet.

Mathematically, the percentage change in electrical resistance due to the applied magnetic field is defined as:

$$
M R \%=\frac{\left[R(H)-R\left(H_{0}\right)\right]}{R\left(H_{0}\right)} \times 100
$$

where $R(H)$ is the resistance of the film as a function of the magnetic field, $H$, and $R\left(H_{0}\right)$ is the resistance of the film at zero applied field.

Pulsed-current electrodeposition is one of the preferred electrochemical methods in which magnetic alloys can be grown via reducing the reaction of metal ions from a single electrolyte [28]-[32]. It has many merits over non-aqueous deposition methods. For example, pulse electrodeposition is a room temperature technology, which offers precision in growth on an atomic scale. The pulse electroplating set-up is usually simple. It is also one of the cost effective deposition methods as compared to its high vacuum depositing counterparts. The electrical and magnetic properties can be easily manipulated by controlling the film composition (i.e., pulse amplitude) and thicknesses (i.e., pulse widths) of either $\mathrm{Co}$ or Au layers on the atomic scale. Also, it does not require 
extensive training to deposit films using pulsed-current electrochemical deposition method [33].

The magnetic properties of the Co-Au alloys are influenced by the size of the Co grains and their separation from $\mathrm{Au}$ grains [7]. The mean Co grain size is estimated as:

$$
K_{A} v=25 k_{B} T_{B}
$$

Where $K_{A}$ is the magnetic anisotropy energy density constant for face-centered cubic Co, $v$ is the volume of a super paramagnetic $\mathrm{Co}$ grain corresponding to the blocking temperature $T_{B}$, and $k_{B}$ is the Boltzmann's constant. The blocking temperature was obtained from the zero-field-cooled (ZFC) curves measured by radio frequency-Superconducting Quantum Interface Device (rf-SQUID) meter. This measurement is extremely sensitive to grain interactions and provides a good technique for investigating the energy barrier distribution [34].

Some of the earliest studies on the Co-Au alloys prepared via pulsed-current electrodeposition in aqueous electrolytes have examined their microstructure, magnetization, and magnetoresistance effects [35], [36]. Guo et al. [35] reported room temperature MR of $0.5 \%$ for the as-deposited $\mathrm{Co}-\mathrm{Au}$ alloys and of up to $1.5 \%$ when annealed at $573 \mathrm{~K}$. They found that the grain size of Co increased with the increase of annealing temperature. Previous studies [37], [38] have shown GMR values of up to $4 \%$ for the as-deposited $\mathrm{Co} / \mathrm{Au}$ multilayers prepared using pulsed-current electrodeposition in the cyanide solution and demonstrated how closely GMR and magnetic properties are correlated with the layer thickness and composition in the as-deposited $\mathrm{Co} / \mathrm{Ag}$ and $\mathrm{Co} / \mathrm{Cu}$ nanostructures [38], [39]. However, it is not yet fully clear to what extent deposition current density, annealing, and layer thickness have an effect on the grain size and on the electrical and magnetic properties of Co-Au alloys.

Therefore, this study describes the preparation parameters of Co-Au granular alloys grown from a cyanide solution on polyimide substrates using constant-current pulsed electrodeposition. A relationship between the MR ratio, saturation magnetization, and composition of $\mathrm{Co}$, and grain size in the alloys has been investigated. We observed that both the deposition current density and annealing have appreciable effect on the GMR, saturation magnetization, and grain size of Co in the Au matrix.

\section{EXPERIMENTAL PROCEDURES}

Co-Au alloys were prepared using computer-controlled pulsed-current electrodeposition method on 15-nm $\mathrm{Cu}$ (111) layers e-beam evaporated on to polyimide substrates. The circuit used for pulsed-current electrodeposition is described in [33]. The electrolyte consisted of cobalt sulphate $\left[\mathrm{CoSO}_{4} \cdot 7 \mathrm{H}_{2} \mathrm{O}\right]$, potassium gold cyanide $\left[\mathrm{KAu}(\mathrm{CN})_{2}\right]$, sodium citrate $\left[\mathrm{Na}_{3} \mathrm{C}_{6} \mathrm{H}_{5} \mathrm{O}_{7} \cdot 2 \mathrm{H}_{2} \mathrm{O}\right.$ ], and sodium chloride [ $\left.\mathrm{NaCl}\right]$ [38]. The composition of $\mathrm{Co}$ in the electrolyte was changed while keeping the composition of $\mathrm{Au}$ constant. In this way, the $\mathrm{Co}: \mathrm{Au}$ ratio could be varied. The total composition of the electrolyte was varied from 10 to 98 at \% Co, while keeping the $\mathrm{KAu}(\mathrm{CN})_{2}, \mathrm{Na}_{3} \mathrm{C}_{6} \mathrm{H}_{5} \mathrm{O}_{7} \cdot 2 \mathrm{H}_{2} \mathrm{O}$, and $\mathrm{NaCl}$ constant. The electrochemical parameters are listed in Table 1. The purpose of adding $\mathrm{NaCl}$ was to enhance the conductivity of the electrolyte. The $\mathrm{Na}_{3} \mathrm{C}_{6} \mathrm{H}_{5} \mathrm{O}_{7} \cdot 2 \mathrm{H}_{2} \mathrm{O}$ was used to improve processing conditions and material properties [40]. Different current densities in the range of 0.1 to $5 \mathrm{~mA} / \mathrm{cm}^{2}$ were tested to deposit pure $\mathrm{Au}$ and Co-rich films. Only the results of alloy films deposited at the current densities of 1 and 5 $\mathrm{mA} / \mathrm{cm}^{2}$ are presented here.

TABLE I: ELECTROCHEMICAL PARAMETERS

\begin{tabular}{|c|c|}
\hline Constituents & $\mathrm{g} / 1$ \\
\hline $\mathrm{CoSO}_{4} .7 \mathrm{H} 2 \mathrm{O}$ & $28-39$ \\
\hline $\mathrm{KAu}(\mathrm{CN})_{2}$ & $15-25$ \\
\hline $\mathrm{Na}_{3} \mathrm{C}_{6} \mathrm{H}_{5} \mathrm{O}_{7} .2 \mathrm{H}_{2} \mathrm{O}$ & 76 \\
\hline $\mathrm{NaCl}$ & 2 \\
\hline Current density & $1-10 \mathrm{~mA} / \mathrm{cm}^{2}$ \\
\hline $\mathrm{pH}$ & $4-6$ \\
\hline Temperature & $50 \pm 1{ }^{0} \mathrm{C}$ \\
\hline
\end{tabular}

The alloy films were electrodeposited from an unstirred, cyanide bath, the temperature of which was maintained at 50 $\pm 1{ }^{0} \mathrm{C}$ in a temperature-controlled water bath, under $\mathrm{dc}$ galvanostatic conditions by employing two electrodes in the single electrolyte. The pulsed-current was supplied and controlled by a programmable microcomputer, digital to analog convertor, and a constant current circuit [33]. A pure Co plate was used as the anode electrode with the sample as the cathode maintained at the distance of $2 \mathrm{~cm}$. After deposition, films were cleaned by double distilled water and dried, and immediately wrapped up in paraffin wax paper to avoid from getting oxidized.

The composition of $\mathrm{Co}$ and $\mathrm{Au}$ was determined using atomic flame emission spectroscopy and verified using energy dispersive $\mathrm{x}$-ray analysis in a scanning electron microscope. Magnetoresistance measurements were carried out using a standard four-probe DC technique with an excitation current of $3.0 \mathrm{~mA}$. The magnetic field was applied along the parallel and perpendicular to the direction to current. The contacts consisted of nickel (5-15\% of phosphorus) probes. The details of the measurement scheme are given in [41], [42]. All of the measured magnetoresistance values were negative and the absolute values of the transverse MR are presented here. Magnetization measurements were carried out at room temperature using a vibrating sample magnetometer and rf-SQUID meter at low temperature. The films were heat treated at $573 \mathrm{~K}$ for 30 minutes. The saturation magnetization of the as-deposited and annealed alloys was estimated from the measured magnetization curves. The temperature dependence of zero-field-cooled (ZFC) and field-cooled (FC) magnetizations for the as-deposited and annealed alloy film was studied using an rf-SQUID meter at the magnetic field of 50 Oe.

\section{RESULTS AND DISCUSSIONS}

\section{A. Compositional Analysis}

Fig. 1 shows a correlation between the Co concentration (Co at \%) in the electrodeposited film and Co composition (Co at \%) in the electrolyte at the current densities of 1 and 5 $\mathrm{mA} / \mathrm{cm}^{2}$, respectively. The composition relationship between the deposited film and electrolyte was not linear. Hence it can be concluded that the deposition was of regular type [43]. We observed that the less noble element, i.e., Co, is less readily deposited as compared to Au. The Co concentration in the deposited alloy film is lower at the lesser concentration in the electrolyte. However, the concentration increases abruptly for electrolyte compositions in excess of 50 at \% Co. At the current density of $1 \mathrm{~mA} / \mathrm{cm}^{2}$, the curve does not saturate even 
with the increasing Co composition in the solution. However, at the current density of $5 \mathrm{~mA} / \mathrm{cm}^{2}$, the Co composition in the film approached to the Co composition in the electrolyte. Also, the concentration of $\mathrm{Au}$ atoms in solution was very small as compared to Co. Hence the deposition of Au atoms seems to be under the diffusion control [43].

TABLE II: ELECTROCHEMICAL COMPOSITION

\begin{tabular}{|c|c|c|c|c|c|c|}
\hline \multicolumn{7}{|c|}{ Electrolyte } \\
\hline$(\mathrm{g} / \mathrm{l})$ & 10 & 30 & 50 & 70 & 90 & 98 \\
\hline $\mathrm{CoSO}$ & 0.35 & 1.1 & 2.55 & 5.85 & 22 & 92.5 \\
$\mathrm{KAu}(\mathrm{CN})_{2}$ & 2.5 & 2.5 & 2.5 & 2.5 & 2.5 & 2.5 \\
$\mathrm{NaCl}$ & 5 & 5 & 5 & 5 & 5 & 5 \\
$\mathrm{Na}_{3} \mathrm{C}_{6} \mathrm{H}_{5} \mathrm{O}_{7}$ & 5 & 5 & 5 & 5 & 5 & 5 \\
\hline
\end{tabular}

The composition of $\mathrm{Co}$ was changed while keeping the composition of $\mathrm{Au}, \mathrm{NaCl}$, and $\mathrm{Na}_{3} \mathrm{C}_{6} \mathrm{H}_{5} \mathrm{O}_{7}$ constant. The amount of $\mathrm{Na}_{3} \mathrm{C}_{6} \mathrm{H}_{5} \mathrm{O}_{7}$ and $\mathrm{NaCl}$ was kept constant to $5 \mathrm{~g} / \mathrm{l}$. The electrochemical parameters are shown in Table 2. The Co concentration in the electrolyte was changed while keeping the concentration of Au constant: Thus, the ratio between the $\mathrm{Co}$ and $\mathrm{Au}$ changed. The inset in Fig. 1 demonstrates the correlation between the Co composition in the Co-Au alloys and the deposition current density. It shows that the composition of $\mathrm{Co}$ in the film drastically increases with the increase in current density.

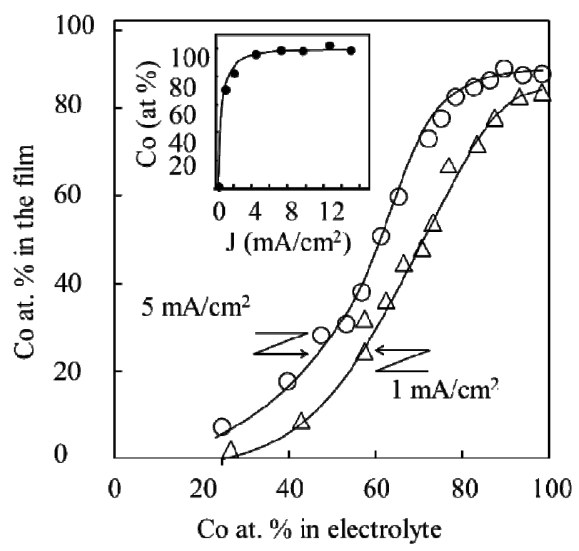

Fig. 1. Co concentration in the deposited alloy versus Co concentration in the electrolyte as the composition of Co in the electrolyte is changed from 10 to 98 at $\%$. Open triangles $(\Delta)$ correspond to the current density $(\mathrm{J})$ of $1 \mathrm{~mA} / \mathrm{cm}^{2}$ and open circles $(\mathrm{O})$ correspond to the current density of $5 \mathrm{~mA} / \mathrm{cm}^{2}$. The inset in it shows the extent to which Co composition (at \%) in the deposited alloy film increases with the deposition current density as it is increased from 0 to $16 \mathrm{~mA} / \mathrm{cm}^{2}$.

\section{B. Composition Dependence of Magnetoresistance Ratio}

Fig. 2 shows the dependence of the MR ratio on the Co concentration for $\mathrm{Co}-\mathrm{Au}$ single layers deposited at current densities of 1 and $5 \mathrm{~mA} / \mathrm{cm}^{2}$, and measured at room temperature and within an magnetic field of $21 \mathrm{kOe}$. The maximum MR ratio of the films deposited at $1 \mathrm{~mA} / \mathrm{cm}^{2}$ was $2 \%$. With an increase in current density to $5 \mathrm{~mA} / \mathrm{cm}^{2}$, the MR ratio increased appreciably for all Co concentrations in the film. The maximum MR ratio was $4.5 \%$ and the concentration of the maximum MR ratio shifted slightly towards the lower Co concentrations. The maximum MR ratio appeared within a narrow concentration range of ferromagnetic atoms even at varying current densities.

The increase in the MR ratio near 30 at \% Co seems to be due to the optimum size and distribution of Co grains and inter-granular separation [44], [37]. The low MR values below 30 at $\%$ Co can be ascribed to a relatively low concentration of ferromagnetic components leading to fewer magnetic and non-magnetic interfacial scattering sites. The decrease in MR values above 45 at \% Co seems to be due to the decrease in spin-dependent scattering, which is mainly responsible for the GMR effect [3], [22], [23]. The increase in the MR ratio with increasing deposition current density is because of a change in microstructure of the film [22], [38]. The current density, composition, and the maximum MR ratio obtained from the experiment are summarized in Table 3.

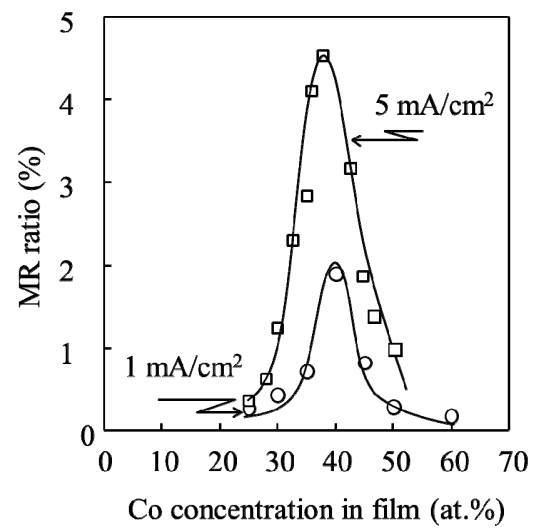

Fig. 2. The MR ratio is plotted as a function of Co concentration (at \%) in the deposited alloy film as the current density is changed from 1 to $5 \mathrm{~mA} / \mathrm{cm}^{2}$. Open squares ( $\square$ ) correspond to the MR ratio measured at the current density of $5 \mathrm{~mA} / \mathrm{cm}^{2}$ and open circles $(\mathrm{O})$ correspond to the MR ratio curve measured at the current density of $1 \mathrm{~mA} / \mathrm{cm}^{2}$.

TABLE III: PHYSICAL PARAMETERS

\begin{tabular}{|c|c|c|}
\hline $\begin{array}{c}\text { Current Density } \\
\left(\mathrm{J} / \mathrm{m}^{2}\right)\end{array}$ & $\begin{array}{c}\text { Composition } \\
(\text { Co at } \%)\end{array}$ & $\begin{array}{c}\text { MR ratio } \\
(\%)\end{array}$ \\
\hline 1 & $0 \sim 60$ & 2 \\
\hline 5 & $0 \sim 60$ & 4.5 \\
\hline
\end{tabular}

\section{Composition Dependence of Saturation Magnetization}

Fig. 3 illustrates the composition dependence of the saturation magnetization for the as-deposited and annealed $\mathrm{Co}-\mathrm{Au}$ alloy films. We observed that the magnetization decreased as the Co concentration was changed for both types of alloys deposited at the current density of 1 and $5 \mathrm{~mA} / \mathrm{cm}^{2}$. In both cases, the magnetization decreased with the increase of Au at $\%$ in the film. The trend of decreasing magnetization with the increasing Au composition is consistent to the results observed for Ni-Cu and Ni-Zn alloys [23]. The decrease in saturation magnetization with the increase of interaction of $4 \mathrm{~s}$ electrons of $\mathrm{Au}$ with the $3 \mathrm{~d}$ electrons of $\mathrm{Co}$ is considered to be the main factor in minimizing the overall magnetic moment of $\mathrm{Co}$ in the Co-Au alloys as the composition of $\mathrm{Au}$ is increased. This explanation holds well with the explanation given in [23]. Also, there was a sharp decrease in magnetization with the increase in current density. Additional investigations are needed to answer the phenomena behind a sharp decrease of magnetization with the increase of current density. For this purpose, results of rf-SQUID meter will be presented in the later section. It seems that the Co-Au alloys electrodeposited at higher current densities either formed smaller grain sizes or formed solid solution. Similar results have been reported for other ferromagnetic films as well [45], [34]. The saturation magnetization of $\mathrm{Co}-\mathrm{Au}$ alloys further decreased with the 
increase of annealing temperature due to the decrease in Co grain size, increase in $\mathrm{Au}$ grain size, and the change in the separation between the Co grains.

The magnetization also deviated from the simple dilution law: It decreased with increasing $\mathrm{Au}$ concentration and vanished below 30 at \% Co. The saturation magnetization decreases sharply with the increase of $\mathrm{Au}$ at $\%$ composition. However, the decrease is more abrupt for the alloys deposited at $5 \mathrm{~mA} / \mathrm{cm}^{2}$ as compared to $1 \mathrm{~mA} / \mathrm{cm}^{2}$.

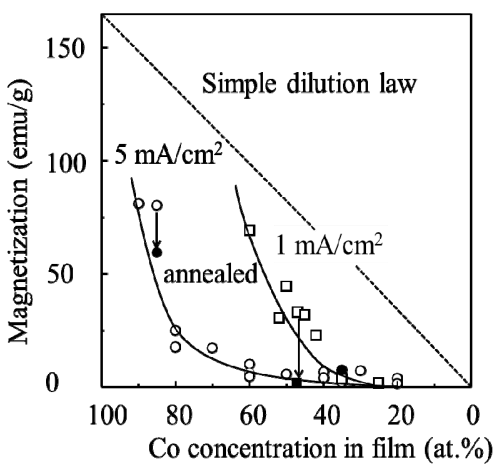

Fig. 3. Saturation magnetization plotted as the concentration of $\mathrm{Co}$ is changed from 0 to $100 \%$ for the as-deposited and annealed $(573 \mathrm{~K}$ for 30 minutes) Co-Au alloys. Open squares ( $\square$ ) and open circles (O) represent magnetization measured at the current densities of 1 and $5 \mathrm{~mA} / \mathrm{cm}^{2}$, respectively. Similarly, closed rectangles $(\boldsymbol{\square})$ and closed circles $(\bullet)$ represent saturation magnetization of the annealed $\mathrm{Co}-\mathrm{Au}$ alloys. The dotted straight line drawn from the magnetization of $160 \mathrm{emu} / \mathrm{g}$ to zero represents simple dilution law.

\section{Microstructural Analysis}

$\mathrm{X}$-ray diffraction spectra of $\mathrm{Co}_{35} \mathrm{Au}_{65}$ alloy films deposited at the current density of $1 \mathrm{~mA} / \mathrm{cm}^{2}$ and $5 \mathrm{~mA} / \mathrm{cm}^{2}$ obtained from Rigaku $C u K \alpha$ X-ray diffractometer are illustrated in Fig. 4, where the prominent broad peak at $2 \theta=44.25^{0}$ corresponds to (111) fcc-Co crystallites and is less intense compared to the peak due to (111) Au: The pure Au (111) and $\mathrm{Au}$ (200) peaks are located at $2 \theta=38.2^{\circ}$ and $2 \theta=44.37^{\circ}$, respectively. The peak height of $\mathrm{Au}$ (111) reduces significantly when the deposition current density increased to $5 \mathrm{~mA} / \mathrm{cm}^{2}$ from the applied current density of $1 \mathrm{~mA} / \mathrm{cm}^{2}$. The peak at $2 \theta=43.25^{\circ}$ corresponds to the $\mathrm{Cu}$ substrate.

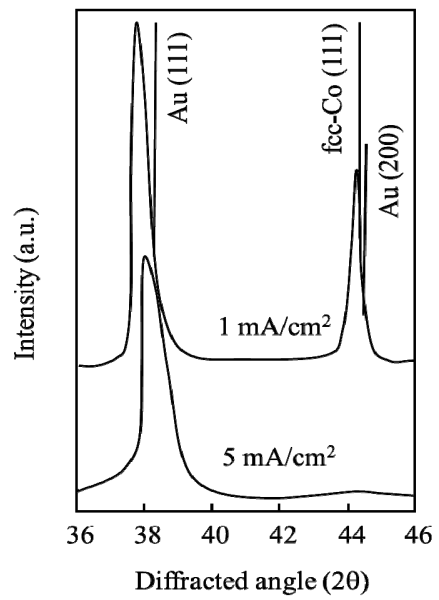

Fig. 4. X-ray diffraction patterns for the as-deposited $\mathrm{Co}_{35} \mathrm{Au}_{65}$ alloys as a function of the current density ( 1 and $5 \mathrm{~mA} / \mathrm{cm}^{2}$ ) as the diffraction angle, $2 \theta$ is changed from 36 to $46^{\circ} . \backslash$

The presence of strong peaks of $\mathrm{Au}$ indicates that $\mathrm{Au}$ here served as the film matrix whereas Co grains are dispersed as small clusters throughout the film: The grain size of the Co was determined using a low temperature rf-SQUID magnetization measurement, and is described below. This result is consistent with the recently reported transmission electron microscopy image of Co-Au nano-composites that shows a clear formation of Co grains with the diameter in the range of 1- $3.3 \mathrm{~nm}$ dispersed in the Au matrix [35]. This is also somewhat analogous to the recently reported X-ray diffraction analysis, which shows the formation of Au grains in $\mathrm{Co}_{68} \mathrm{Au}_{32}$ granular alloys [11].

\section{E. Estimation of Cobalt Grain Size}

Fig. 5 shows the temperature dependence of zero-field-cooled (ZFC) and field-cooled (FC) magnetization for the Co-Au alloy films in the (a) as-deposited and (b) annealed states. During the magnetization measurement, the samples were first cooled to $5 \mathrm{~K}$ at the magnetic field of 50 Oe. However, the magnetic moment was measured during the heating cycle in the range of $5 \mathrm{~K}$ to $300 \mathrm{~K}$. In the as-deposited sample, a broad peak was observed near the temperature of $65 \mathrm{~K}$ at the deposition current density of 5 $\mathrm{mA} / \mathrm{cm}^{2}$.

If the peak of the ZFC curve is the mean blocking temperature observed for super-paramagnetic behavior, the existence of the peak at the lower temperature suggests that the very fine grains of the ferromagnetic $\mathrm{Co}$ or $\mathrm{Co}-\mathrm{Au}$ alloy phase may have been precipitated and they had a wide distribution in size [35]. Since the Co-rich magnetic grains were present in the matrix as a fcc phase, taking $K_{A}$ equal to $5.5 \times 10^{17} \mathrm{eV} / \mathrm{cm}^{3}\left(1 \mathrm{eV}=1.6 \times 10^{-19} \mathrm{C}\right)$ corresponding to the bulk fcc-Co, the volume of the grain could be calculated. Assuming spherical shapes of the grains, the estimated mean cobalt grain diameter corresponding to the blocking temperature was estimated to be approximately $4 \mathrm{~nm}$. We also calculated the grain size of Co for the samples deposited at the current density of $1 \mathrm{~mA} / \mathrm{cm}^{2}$, and found that the grain are larger when deposited at the lower current densities.
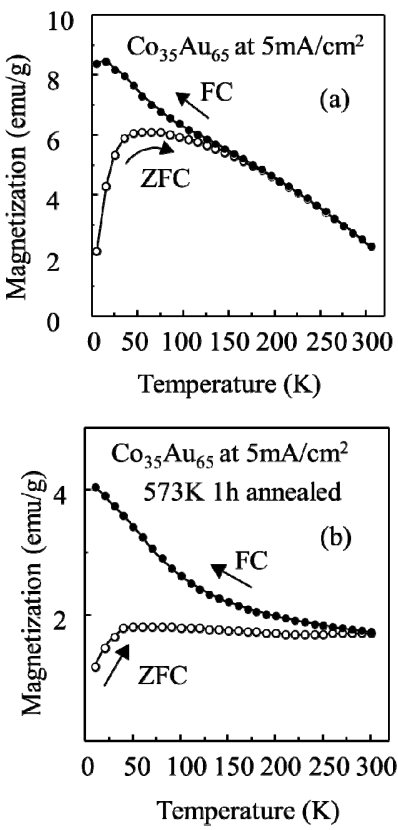

Fig. 5. The saturation magnetization of (a) as deposited and (b) annealed $\mathrm{Co}_{35} \mathrm{Au}_{65}$ alloys as the temperature is changed from 5 to $298 \mathrm{~K}$ : Closed circles $(\bullet)$ indicate the field cooled (FC) curve when the temperature is changed from $298 \mathrm{~K}$ to $5 \mathrm{~K}$ at 50 Oe and open circles (o) indicate the zero-field cooled (ZFC) when the temperature is increased $5 \mathrm{~K}$ to $298 \mathrm{~K}$ at zero applied magnetic field. 
As shown in Fig. 5(b), unlike the broad peak observed at $65 \mathrm{~K}$ for as-deposited alloys (Fig. 5(a)), the peak for the annealed Co-Au alloy is not significant. The peak extends all the way to the room temperature, i.e. the bifurcation of ZFC and FC curves occurs at only close to the room temperature $(\sim 300 \mathrm{~K})$ for the annealed film. This suggests that the grain size of Co had a range of blocking temperatures. This also suggests a change in the size and interaction effects of Co grains in the Au matrix with a wide distribution range. These results are consistent with the results of the low temperature magnetizations of $\mathrm{Co}-\mathrm{Cu}$ [30] and $\mathrm{Co}-\mathrm{Ag}$ [34] films. It is possible that the small cobalt grains present in $\mathrm{Co}-\mathrm{Au}$ films deposited at the current density of $5 \mathrm{~mA} / \mathrm{cm}^{2}$ contributed to the larger MR values for these films [44].

\section{CONCLUSIONS}

Co-Au granular alloys have been prepared by using computer-controlled pulsed-current electrodeposition. The MR ratio and grain size in the film largely depended on the current density. The maximum MR ratio of $\mathrm{Co}_{35} \mathrm{Au}_{65}$ alloy deposited at the current density of $5 \mathrm{~mA} / \mathrm{cm}^{2}$ was $4.5 \%$ at 40 at $\% \mathrm{Co}$. The temperature dependence of the magnetization curves at low temperature suggested the formation of fine grains exhibiting super-paramagnetic behavior. It is considered that the presence of small Co grains in the as-deposited films at $5 \mathrm{~mA} / \mathrm{cm}^{2}$ contributed to the larger MR values for these films. Also, the temperature dependence of magnetization of annealed $\mathrm{Co}_{35} \mathrm{Au}_{65}$ alloys at $573 \mathrm{~K}$ suggests that a decrease in magnetization correlates with the size and distribution of Co grains and their separation from Au grains in the Co-Au matrix. This work is significant because of its usefulness in developing electronic devices based in magnetic technology for the application in the automobile and biomedical sectors.

\section{ACKNOWLEDGMENT}

The authors thank Parshu R. Gyawali, Laboratory for Nanospintronics and Nanoelectronics, Catholic University of America, Washington DC, and Shigeyuki Murayama, Division of Applied Physics, Muroran Institute of Technology, Hokkaido, Japan for fruitful discussions.

\section{REFERENCES}

[1] S. S. P. Parkin, "Giant magnetoresistance in magnetic nanostructures," Annu. Rev. Mater. Sci. vol. 25, pp. 357-388, 1995.

[2] M. N. Baibich, J. M. Broto, A. Fert, F. N. Van Dau, F. Petroff, P. Etienne, G. Creuzet, A. Friederich and J. Chazelas, "Giant Magnetoresistance of (001)Fe/(001)Cr magnetic superlattices," Phys. Rev. Lett. vol. 61, pp. 2472, 1988.

[3] I. Inoue, A. Oguri and S. Maekawa. "Theory of giant magnetoresistance in metallic superlattices," J. Phys. Soc. Jpn. 60pp. 376-385. 1991.

[4] S. Araki, T. Takahata and T. Shinjo, "Magnetism and magnetoresistance of $\mathrm{Au} / \mathrm{Co}$ multilayers," J. Magn. Soc. Japan, vol. 13, pp. 339-342, 1989.

[5] M. Kitada, "Magnetoresistance and microstructure of sputtered Au-Co thin films," J. Magn. Magn. Mater. vol. 208, pp. 244-250, 2000.

[6] E. I. Cooper, C. Bonh, J. Heidmann, Y. Hsu, P. Kern, J. W. Lam, M. Ramasubramanian, N. M. Robertson, L. T. Romankiw and H. Xu, "Recent developments in high-moment electroplated materials for recording heads." IBM J. Res. Dev. vol. 49, pp. 103-126, 2005.

[7] A. Fert and L. Piraux, "Magnetic nanowires," J. Magn. Magn. Mater. vol. 200, pp. 338-358, 10, 1999.

[8] C. P. O. Treutler, "Magnetic sensors for automotive applications," Sens. Actuat. A: Phys. vol. 91, pp. 2-6, 6/5, 2001.
[9] M. H. Kang, B. W. Choi, K. C. Koh, J. H. Lee, and G. T. Park, "Experimental study of a vehicle detector with an AMR sensor," Sens. Actuat. A: Phys. vol. 118, pp. 278-284, 2005.

[10] M. Johnson, "Spintronics," J. Phys. Chem. B, vol. 109, pp 14278-14291, 2005.

[11] P. Boyer, D. MeÌnard and M. Meunier. "Nanoclustered cobalt-gold particles fabricated by femtosecond laser fragmentation in liquids," $J$. Phys. Chem. C 114(32), pp. 13497. 2010.

[12] Y. Xu and J. Wang, "FeCo-Au core-shell nanocrystals," J. Appl. Phys. Lett. vol. 91, pp. 233107, 12/ 3/2007.

[13] Y. H. Xu, J. Bai and J. Wang, "High-magnetic-moment multifunctional nanoparticles for nanomedicine applications," J Magn Magn Mater, vol. 311, pp. 131-134, 4, 2007.

[14] S. Ikeda, T. Houga, W. Takakura and Y. Ueda, "Magnetoresistance in $\left(\mathrm{Co}_{\mathrm{x}} \mathrm{Fe}_{1-\mathrm{x}}\right)_{20} \mathrm{Cu}_{80}$ granular alloys produced by mechanical alloying," Mater. Sci. Eng. A, vol. 217, pp. 376-380, Oct 30, 1996.

[15] V. Y. Zenou, G. Kusinski, L. Yue and G. Thomas, "Structure and magnetic properties of nano-structured heterogeneous Au-Co alloys," vol. 38, pp. 2679-2688, 2003.

[16] C. A. Ross, "Electrodeposited multilayer thin films," Annu. Rev. Mater. Sci. vol. 24, pp. 159-188, 1994.

[17] M. Guan and E. J. Podlaha, "Electrodeposition of AuCo alloys and multilayers," J. Appl. Electrochem., vol. 37, pp. 549, 2007.

[18] Z. Liang Bao and K. L. Kavanagh, "Aligned Co nanodiscs by electrodeposition on GaAs," J. Cryst. Growth, vol. 287, pp. 514-517, $1 / 25,2006$.

[19] K. Y. Yasuhiro H., T. Kingetsu and Y. Masahiko, "In situ observation of epitaxial growth of $[\mathrm{Au} / \mathrm{Co} / \mathrm{Cu}]$ and $[\mathrm{Cu} / \mathrm{Co} / \mathrm{Au}]$ superlattices and their magnetic interface anisotropies," J. Appl. Phys. vol. 90, pp. 5104-5110, 2001.

[20] S. Honda, T. Fujimoto, and M. Nawate, "Giant magnetoresistance of perpendicular magnetic Co/Au multilayers," J. Appl. Phys. vol. 80, pp. 5175-5182, 1996.

[21] U. Hartmann, Ed., Berlin, Heidelberg: Springer Series in Surface Sciences, 2000.

[22] R. F. Soohoo, Magnetic Thin Films. New York: Harper and Row, 1965.

[23] R. M. Bozorth, Ferromagnetism. New York: Van Nostrand, 1947.

[24] D. W. K. Spörl. "Interface anisotropy and chemistry of magnetic multilayers: Au/Co, Pt/Co and Pd/Co," J. Magn. Magn. Mater. 93 pp. 379. 1991.

[25] E. Kolb, M. J. Walker, E. Vélu, M. A. Howson, P. Veillet, D. Greig, J. P. Renard and C. Dupas, "Giant magnetoresistance of dissymmetrical Co/Au multilayers," J. Magn. Magn. Mater. vol. 156, pp. 377-378, 4/2, 1996

[26] C. Rizal, "Study of magnetic anisotropy and magnetoresistance effects in ferromagnetic $\mathrm{Co} / \mathrm{Au}$ multilayer films prepared by oblique incidence evaporation method," J. Magn. Magn. Mater. vol. 310, pp. e646-e648, 2007.

[27] D. S. Geoghegan, A. Hütten, K. H. Müller and L. Schultz, "Magnetoresistance of melt-spun Au-Co," J. Magn. Magn. Mater. vol. 177-181, pp. 1478-1479, 1, 1998.

[28] Y. Ueda, N. Hataya and H. Zaman, "Magnetoresistance effect of $\mathrm{Co} / \mathrm{Cu}$ multilayer film produced by electrodeposition method," $J$ Magn Magn Mater, vol. 156, pp. 350-352, 4/2, 1996.

[29] A. Yamada, M. Shirota, T. Houga, C. Rizal and Y. Ueda, "Electric and magnetic properties of $\mathrm{Fe}-\mathrm{Ni}$ based particle and multilayer films produced by pulse control electrodeposition method," J. Japan Institute of Metals, vol. 66, pp. 869-872, 2002.

[30] T. Houga, H. Zaman, S. Chikazawa and Y. A. U. Y. Ueda, "Magnetism and magnetoresistance effect in the $\mathrm{Co}-\mathrm{Cu}$ and $\mathrm{Co}-\mathrm{Ag}$ films produced by pulse electrodeposition," in IEEE International Magnetics Conference, 1999, pp. BT01-BT01.

[31] H. Zaman, S. Ikeda, and Y. Ueda, "Magnetoresistance in Co-Ag multilayers and granular films produced by electrodeposition method," in Magnetics Conference, 1997. Digests of INTERMAG '97., 1997 IEEE International, 1997, pp. BQ-04-BQ-04.

[32] C. Rizal, A. Yamada, and Y. Ueda, "Pulse Electrodeposition of Co/Au multilayers and granular Alloys," Jpn. J. Appl. Surf. Fin., vol. 55, pp. $83,2004$.

[33] A. Yamada, T. Houga, and Y. Ueda, "Magnetism and magnetoresistance of $\mathrm{Co} / \mathrm{Cu}$ multilayer films produced by pulse control electrodeposition method," J. Magn. Magn. Mater., vol. 239, pp. 272-275, 2002.

[34] A. E. Berkowitz, J. R. Mitchell, M. J. Carey, A. P. Young, D. Rao, A. Starr, S. Zhang, F. E. Spada, F. T. Parker, A. Hutten, and G. Thomas. "Giant magnetoresistance in heterogeneous $\mathrm{Cu}-\mathrm{Co}$ and $\mathrm{Ag}-\mathrm{Co}$ alloy films," J. Appl. Phys. 73(10), pp. 5320-5325. 1993.

[35] Z. Guo, M. Moldovan, D. Young, L. Henry, and E. J. Podlahad, "Magnetoresistance and annealing behaviors of particulate $\mathrm{Co}-\mathrm{Au}$ 
nanocomposites," Electrochem. Solid-State Lett. vol. 10, pp. e31-e35, 2007.

[36] S. Valizadeh, E. B. Svedberg, and P. Leisner, "Electrodeposition of compositionally modulated Au/Co alloy layers," J. Appl. Electrochem., vol. 32, pp. 97-104, 2002.

[37] C. Rizal, A. Yamada, Y. Hori, S. Ishida, M. Matsuda, and Y. Ueda, "Magnetic properties and magnetoresistance effect in $\mathrm{Co} / \mathrm{Au}, \mathrm{Ag}$ nano-structure films produced by pulse electrodeposition," Phys. Stat. Solidi C: Conf. vol. 1, pp. 1756-1759, 2004.

[38] C. Rizal and Y. Ueda, "Effect of deposition current density on the magnetoresistance, magnetic and microstructure of the Co-Au nanostructures," in 2nd International Conference on Nanotechnology: Fundamentals and Applications, Ottawa, 2011, .

[39] H. Zaman, A. Yamada, H. Fukuda, and Y. Ueda, "Magnetoresistance effect in $\mathrm{Co}-\mathrm{Ag}$ and $\mathrm{Co}-\mathrm{Cu}$ alloy films prepared by electrodeposition," Journal of the Electrochemical Society, vol. 145, pp. 565-568, 1998.

[40] I. W. Wolf, "Electrodeposition of magnetic materials," Appl. Phys. vol. 33, pp. 1152-1159, 1962.

[41] C. Rizal and Y. Ueda, "Magnetoresistance effect and magnetic properties of strain induced $\mathrm{Co} / \mathrm{Cu}$ multilayer films," in $3 \mathrm{rd}$ International Nanoelectronics Conference (INEC), Hong Kong, China, pp. 927-928, 2010.

[42] C. Rizal and Y. Ueda. "Magnetotransport properties of $\mathrm{Co} / \mathrm{Cu}$ multilayer films". Proceeding of the Joint Intermag-MMM Conference, Washington DC, 2010.

[43] A. Brenner, Ed., Electrodeposition of Alloys Principle and Practice. Academic Press, 1963.

[44] M. Pan, H. Liu, J. Wang, J. Jia, Q. Xue, J. Li, S. Qin, U. M. Mirsaidov, X. Wang, J. T. Markert, Z. Zhang, and C. Shih, "Quantum Growth of Magnetic Nanoplatelets of $\mathrm{Co}$ on $\mathrm{Si}$ with High Blocking Temperature," Nano Lett. vol. 5, pp. 87-90, 12/09; 01/01, 2004.

[45] C. Scheck, P. Evans, R. Schad, G. Zangari, J. Williams, and T. F. Isaacs-Smith, "Structure and magnetic properties of electrodeposited Ni films on n-GaAs(001)," Journal of Physics: Condensed Matter, vol. 14, pp. 12329, 2002.

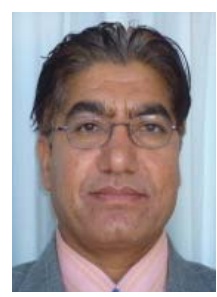

Conrad Rizal has been a member of IACSIT since June 2011. Conrad did his Master of Engineering in nanoelectronics at Muroran Insitute of Technology, Hokkaido, Japan, in 2001. He worked in different industries in Qatar, Nepal, and Japan. In 2006, Conrad joined University of British Columbia as a PhD student Conrad's expertise are in the field of experimental condensed matter physics, nano-fabrication of metallic thin films, magnetic technology, and design and fabrication of optical switches and biosensors on silicon on insulator (SOI) technology. He has several years of research and professional experience in Nepal, Qatar, Japan, and Canada. During his ongoing PhD studies, he designed many high speed switches, thermal sensors, and biosensors on SOI technology. He holds over 15 peer reviewed articles and over 40 conference proceedings. Mr Rizal is a recipient of Japanese government's prestigious Monbu-kagakusho (Ministry of Science, Culture, and Education) scholarship in his MSc study, and Canadian government's Natural Science and Engineering Research Council (NSERC) PGS-D3 scholarship during his $\mathrm{PhD}$ study. Mr Rizal is a member of the Institute of Electrical and Electronics Engineers (IEEE) Inc., and Charter Electrical Engineer (C.Eng.) of The Institute of Engineering and Technology (IET), UK since 2005.

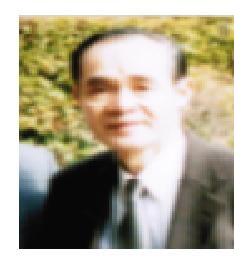

Ueda Yuji received his Doctorate degree in physics from Tohoku University in 1973. He joined Muroran Institute of Technlogy in 1974 and since then served this institute for over 35 years until he took retirement for teaching in 2004. His current status is Professor Emeritus at the Department of Electrical and Electronic Engineering, Muroran Institute of Technology, Hokkaido, Japan. His research interests include fundamental studies and growth and fabrication of magnetic nanostructures using pulsed-current electrodeposition, mechanical alloying, and electron beam evaporation with a target in biomedical applications. Dr. Ueda was a recipient of many research excellence awards by the Japanese government. He has published over 100 research journal articles.

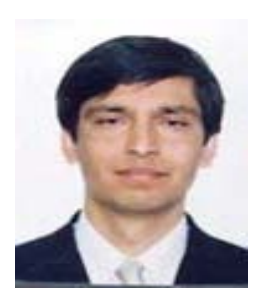

Ramesh Pokharel received his Doctorate degree in electrical engineering from the University of Tokyo, Japan in 2003. He had short academic and industrial experiences in Nepal before he joined the University of Tokyo in 1997 as a research student. He had been a post-doctoral research fellow with the Department of Electrical Engineering and Electronics, Aoyama Gakuin University, Japan from April 2003 to March 2005. In April 2005, he joined the Department of Electronics, Graduate School of Information Science and Electrical Engineering, Kyushu University, and since September 2010, he has been a Professor at the Center for Japan-Egypt Cooperation in Science and Technology, Kyushu University. His current research interests include the low cost RFIC and analog circuits for microwave and millimeter wave wireless communications, on-chip integrated antennas and filters, and on-chip meta-materials in CMOS. He is a member of the IEEE. Dr. Pokharel was a recipient of the Monbu-Kagakusho Scholarship of the Japanese Government from 1997-2003, and an excellent COE research presentation award holder at the University of Tokyo in 2003. 